\title{
Entrepreneurship
}

Jul a Dez 2018 - v.2 - n.2

ISSN: 2595-4318

This article is also available online at: www.sustenere.co

\section{A importância da controladoria e da função do controller no processo de tomada de decisão na gestão empresarial}

Este estudo tem como objetivo analisar a importância da controladoria e a função do controller no processo de tomada de decisão na gestão empresarial. Ao descrever e apresentar mudanças no ambiente organizacional e procurar desenvolver instrumentos para tomada de decisões, este artigo visa aumentar a participação no mercado das ferramentas de planejamento e controle para se tornar eficaz a gestão empresarial, levando em conta um crescimento em longo prazo no âmbito territorial ao qual está firmada a organização. A pesquisa está enfocada nos aspectos específicos da identificação das vantagens e benefícios que a controladoria traz para as empresas; caracterizando as principais funções do controller dentro das empresas e analisando, a partida a literatura estudada, a importância do controller no planejamento da empresa. É fundamental dar ênfase a tomada de decisão ao criar estratégias para a definição do público-alvo, determinando-se as vantagens e as desvantagens, e principalmente, dos benefícios que a controladoria traz para as empresas, além de agregar conhecimentos sobre a área de atuação do contador. A natureza da pesquisa é qualitativa. A pesquisa classifica-se quanto aos fins, em exploratória e descritiva e quanto aos meios a pesquisa está classificada em bibliográfica. $O$ estudo não tem a pretensão de exaurir o tema levantado, ao contrário quer apenas servir como estímulo para que novos estudos sejam realizados e novas opiniões surjam, enriquecendo a matéria.

Palavras-chave: Controladoria; Processo de Tomada de Decisão; Gestão Empresarial.

\section{The importance of controlling and control function in the decision- making process in business management}

\begin{abstract}
This study aims to analyze the importance of controller and the role of the controller in the process of decision making in business management. In describing and presenting changes in the organizational environment and seeking to develop tools for decision making, this article aims to increase the market share of planning and control tools to become effective business management, taking into account a long term growth in the territorial scope to which the organization is established. The research is focused on the specific aspects of identifying the advantages and benefits that the controller brings to the companies; characterizing the main functions of the controller within the companies and analyzing, starting the studied literature, the importance of the controller in the planning of the company. It is essential to emphasize the decision-making process when creating strategies for the definition of the target audience, determining the advantages and disadvantages, and mainly, the benefits that the controller brings to the companies, besides adding knowledge about the area of performance of the meter. The nature of research is qualitative. The research is classified as exploratory and descriptive, and as to the means the research is classified in bibliographical. The study does not pretend to exhaust the theme raised, rather it only serves as a stimulus for new studies to be carried out and new opinions to emerge, enriching the subject.
\end{abstract}

Keywords: Controller; Decision Making Process; Business Management.

Topic: Finanças Empresariais

Reviewed anonymously in the process of blind peer.
Received: 17/01/2018

Approved: 15/04/2018

Clésia dos Santos Silva (iD)

Faculdade Uninassau Aracaju, Brasil

http://lattes.cnpq.br/2222081352510618

http://orcid.org/0000-0002-3297-952X

clesiassilva13@hotmail.com

Alvani Bomfim de Sousa Júnior (DD

Faculdade Uninassau Aracaju, Brasil

http://lattes.cnpq.br/6358502728889050

http://orcid.org/0000-0002-8714-4175

alvanijunior@yahoo.com.br

Referencing this:

SILVA, C. S.; SOUSA JÚNIOR, A. B.. A importância da controladoria e da função do controller no processo de tomada de decisão na gestão empresarial. Entrepreneurship, v.2, n.2, p.17-29, 2018. DOI: http://doi.org/10.6008/CBPC2595-4318.2018.002.0002 


\section{INTRODUÇÃO}

Através do crescente aumento da competitividade que se tem verificado no cenário econômico nacional e as constantes mudanças no ambiente organizacional nota-se que as empresas procuram desenvolver instrumentos de tomadas de decisões visando manter ou mesmo aumentar sua participação no mercado. Assim, a controladoria deve adequar-se a estas necessidades para contribuir na busca dos objetivos da organização.

Estão emergindo, no mundo, diversas ferramentas e processos padronizados que, quando implantados, auxiliam sobremaneira a gestão empresarial. Com a atual competição dos negócios e as constantes mudanças nos diversos ambientes das empresas exigem-se a maximização do desempenho e do controle gerencial. Desta forma, a controladoria e o controller exercem papel preponderante na empresa, apoiando os gestores no planejamento e controle de gestão, através da manutenção de um sistema de informações que permita integrar as várias funções e especialidades.

Com o processo de planejamento e controle das operações empresariais desenvolve-se uma visão de modelo de gestão, consequentemente, uma gestão eficaz das informações, financeiras e econômicas, necessárias à empresa apresentando um grau máximo de eficácia na relação de custo/benefício da geração da comunicação da informação.

Neste trabalho, mostra-se então que o mercado globalizado com regime de livre comercio, o alvo da empresa é auferir o maior lucro possível conjuntamente com o crescimento em longo prazo atingindo o bemestar da comunidade na qual está inserido. Os consumidores são hoje mais exigentes e isso torna o mercado bastante dinâmico, com constantes mudanças, exigindo das empresas um processo de planejamento visando a melhoria do desempenho e controle, eficiente para atingir o objetivo, o controller tem um papel fundamental e importante para dar suporte na tomada de decisões, na estratégia das relações com o mercado consumidor, desde a definição de seu público alvo, otimizando o orçamento, e maximizando o resultado econômico das atividades e áreas de cada empresa. Através de um processo de planejamento e mensuração que demonstra a execução das atividades, visando os objetivos das empresas, que além do lucro, se estendem a atingir um crescimento seguro, onde a empresa deva aplicar métodos eficientes com base na análise da performance demonstrada da empresa onde os recursos da controladoria estão à disposição. Será que a Controladoria e o controller são necessários para uma gestão eficiente na tomada de decisões?

A função controller, na administração financeira é a observação e controle da cúpula administrativa, fornecendo dados e informações e enxergando os possíveis pontos de estrangulamentos atuais ou futuros onde pode se colocar a empresa, orientando para o controle da rentabilidade, definição de investimento e aplicações.

O controller deve medir as possibilidades da empresa também perante as realidades externas. Deve estabelecer políticas básicas, fixar objetivos com estabelecimentos de padrões de controle, criação de estruturas, para tomadas de decisões e elaborar métodos eficientes. 
Em vista do cenário supra exposto, desenha-se como objetivo central do presente trabalho é analisar a importância da controladoria e a função do controller no processo de tomada de decisão na gestão empresarial. Para isso, determinam-se como objetivos específicos identificar as vantagens e benefícios que a controladoria traz para as empresas; caracterizar as principais funções e do controller dentro das empresas e analisar a partida a literatura estudada a importância do controller no planejamento da empresa.

Para tanto justifica-se a elaboração deste estudo pelo interesse para os pesquisadores em suas atividades profissionais atuais e principalmente futuras. E a literatura existente é muito incipiente e percorre caminhos que nem sempre proporcionam o entendimento imediato ou a solução para as dificuldades sugeridas durante o desenvolvimento desta função. Onde a importância pessoal deste estudo é de agregar conhecimento sobre esta área de atuação do contador.

No universo da gestão empresarial, a metodologia utilizada conforme Roesch (1999) metodologia é o conjunto de métodos utilizados na busca do conhecimento. O método utilizado é o indutivo, por percorrer um caminho estabelecido uma conexão ascendente, do particular para o geral. Neste sentido, o artigo traz nas próximas sessões uma revisão teórica, uma metodologia que aponta os caminhos trançados e por fim as conclusões obtidas.

\section{METODOLOGIA}

Entende-se por Metodologia o estudo dos métodos utilizados ou então, as etapas a se seguir num determinado processo. Partindo dessa tese, ela se torna indispensável e em todo e qualquer trabalho. Para o desenvolvimento de uma pesquisa ou trabalho científico, há uma diversidade de procedimentos a serem tomados para a obtenção de dados referente à pesquisa que está sendo feita ou trabalhada. Segundo Silva (2010), "a metodologia relaciona-se com os objetivos e a finalidade do projeto. Deve descrever os passos dados para alcançar os objetivos"

A metodologia utilizada para elaboração deste artigo foi levando em consideração a natureza do problema de pesquisa e os objetivos a serem alcançados nesse estudo, a pesquisa utilizada é um resumo que dispensa a originalidade, feito a partir de uma pesquisa bibliográfica fundamentada em trabalhos científicos originais sobre estudos da controladoria, trabalho avançados, publicados por autoridades no assunto, que trouxeram grandes constituições. Onde foi desenvolvido uma pesquisa exploratória cuja finalidade é constitui um trabalho preliminar ou proporcionar maiores informações sobre determinado assunto. Segundo Lakatos (2002) a pesquisa exploratória é realizada em áreas na qual há pouco conhecimento acumulado.

O estudo bibliográfico, porém, não se limita à cópia das ideias, partindo dos pressupostos e utilizando a metodologia adequada, dando o enfoque ao estudo do trata da controladoria e da função controller. Dessa forma, a pesquisa qualitativa representa um propriedade de ideias, coisa e pessoas que permite que sejam diferenciadas entre as de acordo com sua natureza, possuindo um conteúdo altamente descritivo, onde a coleta está aliada a análise, e pode ainda utilizar-se de instrumentos característicos a pesquisa de natureza quantitativa, incorporada em sua análise, mais o que vai preponderar é o estudo quanto a natureza, do alcance e das intepretações possíveis para o tema estudado de acordo com os objetivos. Logo, a realização 
desses estudos se realizou através de um conjunto de diversas técnicas de pesquisa conforme se cita, para obtenção dos objetivos e checagem da solução do problema levantado.

Dessa forma a presente pesquisa foi de natureza qualitativa, onde segundo Roesch (1999), na pesquisa de caráter qualitativa, os instrumentos de coletadas de dados serão a observação não participante. Também é possível trabalhar com dados existente na forma de arquivos, bancos de dados, índices ou relatórios.

\section{REVISÃO TEÓRICA}

\section{Controladoria e sua Importância}

Del Valle et al. (citado por ARAGAKI, 2002) analisam incialmente que a controladoria se iniciou com um profissional denominado 'controller'. Os autores acima citados expõem que os títulos de 'controller' como tesoureiro tiveram sua origem no governo, na Inglaterra. Desta forma, no século XV o título foi usado em vários cargos da 'English Royal Household', como o 'controller' das contas, logo esses títulos foram estendidos para corporações de negócios através das estradas de ferro, nos Estados Unidos.

A controladoria iniciou-se na Inglaterra e foi na área pública que se deus o marco do seu desenvolvimento. Em seguida, alastrou-se para os Estados Unidos, através das estradas de ferro, do surgimento dos conglomerados comerciais e da participação de inúmeros acionistas em operações financeiras, atingido a inciativa privada.

O termo 'controller' não existia no dicionário brasileiro. Horngren (1985) registrar que "o termo controller (às vezes com p. comptroller, derivado do francês, compte, quer dizer conta) significa o principal executivo da área de contabilidade administrativa". Esse termo sendo incluído na área coorporativa através da influência dos Estados Unidos, Inglaterra e outros países. Tung (1993) diz:

As palavras controller e comptroller eram utilizadas, incialmente, nesses respectivos países, para designar o executivo que tinha a tarefa de controlar ou verificar as contas. Com a evolução industrial e comercial, essa definição tonou-se inadequada, visto não abranger a amplitude das funções do controller.

Nota-se que o significado da palavra controller tinha dimensões ínfimas. Conforme Moisman et al. (1999), "não são todas as empresas que apresentam um órgão designados a executar as funções da controladoria. A ausência deste será suprida por um gestor que tenha uma visa generalista". No que se refere a missão, a controladoria tem a sua no tocante a buscar a otimização dos resultados e a continuidade da organização.

Almeida et al. (1999) destaca que a filosofia de atuação da controladoria atende à: interação e apoio as áreas operacionais; coordenação de esforços visando a sinergia das ações; participação ativa do processo de planejamento; credibilidade, persuasão e motivação e indução as melhores decisões para a empresa como um todo.

Nota-se ainda, nesse contexto, que a controladoria pode ser entendida como um sistema aberto e dinâmico que interage constantemente como o ambiente organizacional. Tal interação ocorre por meio de 
estratégias e planos a serem atingidos através das propostas dos orçamentos e pelo cumprimento dos controles definidos como os gestores.

É de suma importância ressaltar que a controladoria além de ser um conjunto de conhecimentos tem a capacidade de prever os problemas que poderão surgir futuramente, e nas tomadas de decisão coleta todas as informações necessárias para um resultado eficaz, na controladoria podemos usar o Planejamento, e controle para harmonizar os objetivos de uma organização. Nos dias de hoje com tanta tecnologia em um mundo globalizado tem surgido cada vez mais, pequenas microempresas, para definição de suas funções surge a importância da controladoria para alcançar os resultados. A controladoria não de ser vista como um método focalizado no como fazer.

Para uma correta compreensão do todo, de acordo com Almeida et al. (2001), deve-se "cindi-la em dois vértices: o primeiro, como ramo do conhecimento responsável pelo estabelecimento de toda a base conceitual; e o segundo, como órgão administrativo respondendo pela disseminação do conhecimento, modelagem e implantação de sistemas de informações"

Segundo Brito (2003), a controladoria tem juntamente aos gestores a responsabilidade de assegurar os resultados necessários a continuidade da empresa, fornecimento de informações por meio de uma atuação proativa necessário para tomada de decisões. O gerenciamento eficiente dos riscos será determinante na obtenção dos resultados positivos, como também para a melhoria do prestígio do controller na empresa. Conforme Wahlmann (2003) entende que:

A Controladoria constitui uma área das Ciências Contábeis composta por um conjunto de conhecimentos interdisciplinares oriundos da Administração de Empresas, Economia, Informática, Estatística e, principalmente, da própria Contabilidade. Nas organizações representa o segmento responsável por propiciar um processo decisório de qualidade mediante o fornecimento de informações previamente analisadas.

A controladoria dissemina o conhecimento, modelagem necessária para melhoria da organização na implantação de sistema de informação visando melhor atender as necessidades da empresa atingindo os resultados e metas impostas (alçadas).

A informação segundo Floriani (2001) é que cabe à controladoria a transformação dos planos operacionais não quantificados em planos orçamentários, bem como seu acompanhamento posterior, identificando desvios e direcionando a cada área sugestões de medidas necessárias para corrigi-los. 0 processo operacional da controladoria acontece necessariamente com base no sistema de informações adotados pela organização, uma vez que o produto a ser gerado é a informação considerada como necessária para as tomadas de decisões.

O profissional que desenvolver as atividades da controladoria vem se destacando cada vez mais como peça-chave para interpretar e comunicar dados e informações, no sentido de assessorar os gestores, com elevado envolvimento no processo decisório.

A controladoria deve ser entendida como órgão participante essencial para a estrutura organizacional das empresas, tornando-o como uma ferramenta de monitoramento dos efeitos de atos da gestão e sobre os resultados que se espera alcançar, seguindo os métodos da correta tomada de decisão. Também objetiva, sobre as atividades da empresa ao medir e avaliar esses resultados os acompanhando e 
comparando com o desempenho anterior ou de empresas concorrentes do mesmo ramo, identificando assim aos gestores quais os reais resultados alcançados e quais melhorias implementar para na sequência poder apontar os melhores meios para as correções nas atividades organizacionais (RAMBO et al., 2006).

Destaca-se que a controladoria não se responsabiliza somente pelo sistema contábil, mas deve ter um espaço mais amplo dentro da empresa, conhecendo os processos de todas as áreas e o sistema de informação gerencial formado por dados e informações necessárias as tomadas de decisões. Assim, pode-se visualizar a controladoria como uma função da contabilidade que recebe influência de outras ciências, como a administração e economia.

\section{Função do Controladoria vs Controller}

Como a função da controladoria, nota-se que conforme a dimensão da empresa, a controladoria passar a ter maior importância devido as funções que executa, assim em entidades de pequeno porte, as funções da controladoria podem ser executadas diretamente pelo dono da empresa, que participa mais ativamente, desde o processo produtivo até o controle financeiro.

Assim, o acompanhamento estará sendo realizado de forma mais próxima possível, uma vez que devido ao tamanhão da empresa, o controlador (neste caso próprio dono) tem total conhecimento de todos os aspectos relacionados à organização, como por exemplo, o relacionamento com seus clientes e fornecedores, sua situação financeira, a formação de seu pessoal e se os objetivos estabelecidos estão sendo atingidos de maneira satisfatória ou não, além do conhecimento das previsões e expectativas para a empresa.

Porém, com o aumento do porte da organização, crescem também a complexidade das operações e a dificuldade em se manter um controle e acompanhamento efetivo direto de todos os pontos citados. Em função disto, a controladoria passa a ser de fundamental importância, no sentido de prover, aos gestores, informações para a tomada de decisão e para acompanhamento da situação real da empresa. Consequentemente a principal função da controladoria é a de fornecer informações para a tomada de decisões.

Neste contexto, mesmo tendo uma função bastante abrangente, compete a ela a formação de sistema de informação dentro de uma entidade, que permitam relatar: a situação econômico-financeira da empresa; a performance das áreas operacionais; a performance dos gestores das áreas e acompanhamento estratégico.

No sentido de mercado de trabalho, verifica-se que o papel do controller difere grandemente de uma empresa para outra. Dependendo do porte e da estrutura organizacional, a função de controladoria pode, atuando de diferentes formas, ser exercida dentro dos mais diversos níveis da administração. Conforme mostram Peres Junior et al. (1995) essa função pode ser exercida por meio de dois enfoques distintos:

Conforme autores, as funções da controladoria, convergem na mesma direção, destacando o seu relacionamento com a estratégia (KANITZ, 1999). Apesar de as vezes ser confundido com o administrador financeiro, a função básica do controlador consiste em dirigir e, na maioria das vezes implantar os sistemas 
de: informação, motivação, coordenação, avaliação, planejamento e acompanhamento. Mesmo estando dentro do âmbito da informação, uma das mais importantes funções da controladoria atualmente é o acompanhamento e avaliação do desempenho estratégico.

No processo de controle, as suas funções passam a compor um conjunto de atividades administrativas para a gestão. Estas atividades, devem ser interligadas e averiguadas efetivamente para saber se estão sendo executadas conforme os planejamentos originais e se seguem a missão da empresa imposta para alcançar o objetivo empresarial.

Nota-se que todos esses pontos sejam considerados, é fundamental a correta formulação de um planejamento estratégico que contemple a extensão dessas questões, sendo que a correta definição os objetivos almejados pela empresa e sua correlação com estratégia, compatível com a organização, irão proporcionar a controladoria os instrumentos e informações necessários para execução de suas funções.

Assim, a situação da controladoria deve ser direcionada para a visão de negócios. Cabe a ela funções mais importantes do que apenas retratar determinadas situações. Deve-se ter em mente a grande importância das informações que ela possui, no sentido de ser um sistema capaz, de auxiliar as áreas de negócios da empresa, antecipando os resultados e os reflexos que determinada operações podem trazer a empresa.

Segundo Kantiz (1999) o termo controller vem desta o início do século XX pelas grandes corporações norte-americana e dentro da contabilidade ele se deu da seguinte maneira: Tinha como prioridade nos balancetes e no sistema de partidas dobras; valorizavas as finalidades tributárias e imposto de renda; contabilidade gerencial e auditoria; valorização da contabilidade de custo; aperfeiçoamento dos custos e técnicas avançadas e dentre outros. Conforme Ferreira Júnior (2007) diz:

O controller surgiu no início do século XX, dentro da evolução administrativa das grandes corporações americanas, como executivos de confiança, bem como proprietários e acionistas majoritários, normalmente dirigentes de organizações. Entende-se que originalmente tinha como responsabilidade realizar um rígido controle de todos os negócios das filiais localizadas dentro ou fora dos EUA. Já no Brasil essa função só se desenvolveu com a instalação de empresas multinacionais americanas.

O controller é uma função ainda nova nas empresas Brasileiras, teve sua linguagem recentemente incorporadas nos meios comercial e administrativos originados dos EUA e Inglaterra, onde essa função do controller ou 'comptroller' define o executivo dentro da empresa e suas tarefas que são de controlar e verificar as contas.

Para Figueiredo et al. (1993), no Brasil a atividade do controller ainda é algo novo, existem dúvidas a respeito dessas funções dentro das empresas, porém ainda é destacado a integração entre os padrões, orçamentos e contabilidade, que são os principais instrumentos onde se pode mensurar a disposição do controller.

Quando o assunto é controllers, o termo mais usado nas empresas é a eficácia, sempre tendo ao seu lado a controladoria, que é um conceito complexo e no dia a dia é utilizado como se consubstanciasse todos os aspectos benefícios e positivos para as empresas. 
A eficácia numa entidade tem como pilar básico a realização de sua principal função que é o cumprimento de sua missão e, concomitantemente, pela garantia de sua sobrevivência, garantindo os níveis de considerar a otimização o cumprimento da missão e a continuidade da empresa. Depende de sua interação do ambiente onde atua, enfocando a satisfação do cliente, dos funcionários, acionistas, comunidade e a participação junto aos governos etc.

O controller tem enfatizado a busca pela integração das informações, ou seja, esse tipo de procedimento visa dar mais confiabilidade à de informação e ajuda no processo de planejamento e controle contribuindo de alguma forma para a eficiência e eficácia na gestão dos negócios da empresa.

O controller segundo Ronchi (1999), dirigi, gerencia, controla e responde pelos seis departamentos: finanças, planejamento, CPD, contabilidade, $\mathrm{O}$ \& M e auditoria. E na controladoria, responde diretamente ao diretor financeiro, quando o empreendimento é de grande porte ou diretamente ao diretor geral nas empresas de pequeno e médio porte. Neste sentindo, Almeida et al. (2001), lista um conjunto de objetivos ligadas as funções da controladoria:

a) subsidiar o processo de gestão: ajudar o processo de gestão dando suporte e apoio para projeções e simulações sobre eventos econômicos que possam afetar as decisões dos gestores;

b) elaborar a avaliação de desempenho: a controladoria elabora a análise de desempenho de todas as áreas, dos gestores, da empresa e da própria área;

c) apoiar a avaliação de resultado: elaborar a análise de resultado econômico dos produtos e serviços e monitorar e orientar o processo de estabelecimento de padrões.

d) gerenciar os sistemas de informação: realizar a padronização e harmonização das diversas informações econômicas transmitidas aos gestores.

e) atender aos agentes do mercado: através da interação com o meio externo, analisar e mensurar o impacto das legislações no resultado econômico da empresa e apoiar os gestores no atendimento aos diversos agentes do mercado.

Com isso, nota-se que todos esses pontos sejam considerados, é fundamental a correta formulação para um bom planejamento estratégico que contemple a extensão dos objetivos almejados pela empresa e sua correlação com a estratégia para que se atinjam os resultados almejados, a atuação da controladoria.

Desta forma obriga a empresa a refletir sobre suas metas. A meta mais frequentemente buscada pelas empresas é o crescimento e o planejamento financeiro deve ser utilizado para melhor compreender como o crescimento pode ser conseguido.

\section{Processo de Tomada de Decisão}

Podemos dizer que Processo de tomada de Decisão consiste em realizar uma escolha entre várias alternativas, também pode aparecer no contexto para identificação do problema em nosso dia a dia, para tomada de decisão é necessário analisar e conhecer cada processo.

Para identificar os critérios de decisão é preciso determinar pontos relevantes, sejam eles implícitos ou explícitos. Nesse processo também é necessário determinar os pesos desses critérios. Eles devem sofrer uma classificação de importância, ou seja, devem ser atribuídos pesos aos itens para que seja dada a eles a prioridade adequada. Segundo CHIAVENATO (2003) entende-se que: 
A organização é um sistema de decisões em que cada pessoa participa consciente e racionalmente, escolhendo e decidindo entre alternativas mais ou menos racionais que são apresentadas de acordo com sua personalidade, motivações e atitudes. Os processos de percepção das situações e o raciocínio são básicos para a explicação do comportamento humano nas organizações: o que uma pessoa aprecia e deseja influencia o que se vê e interpreta, assim como o que vê e interpreta influencia o que aprecia e deseja. Em outros termos, a pessoa decide em função de sua percepção das situações. Em resumo, as pessoas são processadoras de informação, criadoras de opinião e tomadoras de decisão.

Sabe- se que cada decisão transcendente para uma companhia costuma implicar uma grande reflexão ou investigação, e a colaboração entre equipes multidisciplinares, no âmbito das empresas e dos negócios, a tomada de decisões é uma parte muito importante do management e da gestão. Conforme Simon (1965 citado por OLIVEIRA, 2004) em:

Decisões programadas e decisões não-programadas. As decisões programadas são caracterizadas por serem repetitivas, rotineiras e estruturadas - decisões automatizadas por uma sequência de procedimentos, não necessitando da intervenção do decisor - além de serem permanentes, servindo de norteamento para a definição das metas, objetivos, políticas e procedimentos organizacionais. As decisões não-programadas são caracterizadas pela novidade, além de serem desestruturadas - decisões não automatizadas, que dependem de solução do decisor. A característica da novidade se apresenta porque não existem referenciais anteriores para a resolução do problema ou em razão de sua complexidade, ou porque, para sua resolução, torna-se necessária a implementação de medidas específicas. Essas classificações evidenciam as características do processo de tomada de decisão e permitem a programação do que deverá ser feito durante esse processo.

Toda organização é um sistema de decisões, onde todos os membros estão continuamente tomando alguma decisão, "é impossível pensar a organização sem considerar a ocorrência constante do processo decisório". Pode- se dizer que tomada de decisão não se trata apenas de escolhas, mais que se trata de um processo muito mais abrangente, avalia e compara as alternativas, dando maior oportunidade de crescimento; quanto ao peso atribuído a responsabilidade dos gestores na tomada de decisão.

Ressalta-se que a controladoria utiliza vários ensinamentos contábeis, administrativos e econômicos que interagem entre si com outras ciências, como direito, psicologia, sociologia, matemática, estatísticas e outras, para assessorar o processo decisório dos gestores, agilizar e interprestar dados e informações para auxiliar os gestores e demais usuários que necessitam das suas informações para elabora, acompanhar e analisar o processo de tomada de decisão na gestão.

Assim, tem como finalidade garantir informações adequadas ao processo de gestão e a tomada de decisão, utilizando-se de um sistema de informações que atenda às necessidades da empresa e sirvam de suporte para acompanhar os planos estabelecidos pelos gestores.

\section{Gestão Empresarial}

Suponho que a compra é uma atividade fundamental para qualquer empresa, na gestão empresarial não se trata apenas da fiscalização, é preciso saber o que comprar e quando comprar buscando as melhores condições de negociação que vai melhor atender as necessidades da empresa, planejar é de suma importância para obter êxito em qualquer modalidade na gestão empresarial. O planejamento requer tempo, e estratégias em relação à tomada de decisão. 
Desse modo, um bom gestor deverá saber gerir as suas decisões e estratégia através de uma boa gestão gerencial no qual permite aos administradores empresarial, que se beneficie das informações produzidas através da contabilidade. Podendo assim conhecer a realidade da empresa e tomar decisões com mais segurança.

Para Chiavenato (1994) gerir é "interpretar os objetivos propostos pela empresa e transformá-los em ação empresarial por meio de planejamento, organização, direção e controle de todos os esforços realizados em todas as áreas e em todos os níveis da empresa, a fim de atingir tais objetivos".

Conforme Marion (2009) os responsáveis pela administração estão tomando decisões, quase todas importantes, vitais para o sucesso do negócio. Por isso, há a necessidade de dados, de informações corretas de subsídio que contribuam para uma boa tomada de decisão.

\section{Modelo de Gestão}

Pode- se dizer que a gestão empresarial tem o papel de importante para as organizações além de impulsionar os gestores na liderança e no desenvolvimento de habilidades e competência dos envolvidos nas atividades em áreas específicas.

Para Gramigna (2007, citado por COELHO et al., 2009), trata-se de um conjunto de ferramentas que, reunidas, formam uma metodologia de apoio à gestão de pessoas. As pessoas encontram- se em alta, uma vez que a riqueza das empresas e das nações depende do conhecimento e das habilidades de suas equipes.

O modelo de gestão é em síntese, um grande modelo de controle, pois nele são definidas as diretrizes de como os gestores vão ser avaliados, e os princípios de como a empresa vai ser administrada. Do exposto, depreende-se que o modelo de gestão deve esclarecer a maneira como se pretende delinear a gestão.

\section{Processo de Gestão}

Para Lopes (2007) enfatizar os três pilares da Competência, que consiste na sigla CHA: Conhecimento, Habilidade e Atitude, onde o Conhecimento é o saber, o aprendizado que adquirimos na escola, nos livros, e que acumulamos ao longo da vida. Fazem parte da nossa memória e são capazes de influenciar no nosso comportamento e julgamento; a Habilidade é o saber fazer, é a aplicação do conhecimento, é a capacidade de utilização do conhecimento acumulado na memória de modo prático e produtivo; e a Atitude é o querer fazer, é o que nos impulsiona a executar as nossas habilidades e o conhecimento adquirido.

Logo, para Pereira (1999) entende que o processo de gestão deve assegurar que a dinâmica das decisões tomadas nas empresas conduza-a efetivamente ao cumprimento de sua missão, garantindo-lhe adaptabilidade e o equilíbrio necessário à sua continuidade.

\section{Planejamento}

Como ponto de partida para o desenvolvimento um negócio que dê certo, a necessidade do planejamento é uma das mais importantes atividades do empreendedor. É nesta fase, que o plano de 
negócios se delimita e define aonde quer chegar, identificando as oportunidades do negócio no mercado. (SILVA, 2008).

Todos os planos têm um propósito comum: a previsão, a programação e a coordenação de uma sequência lógica de eventos, os quais se bem-sucedidos, deverão conduzir ao alcance do objetivo que se pretende. Geralmente o plano é um curso predeterminado de ação sobre um período especificado e proporcionam respostas as seguintes questões: o que, quando, como, onde e por quem, na verdade é uma tomada antecipada de decisões sobre o que fazer, antes de a ação ser necessária. Planejar consiste em simular o futuro desejado e estabelecer previamente os cursos de ação necessários e os meios adequados para atingilos. (CHIAVENATO, 2004)

Nakagawa (1993) afirma que o planejamento se configura como um dos instrumentos mais relevantes a controladoria, por servir de base para analisar o suposto comportamento futuro da entidade. Num sentido restrito, envolve a avaliação e tomada de decisões em cenários prováveis, visando atingir uma situação futura desejada. Em sentido amplo, o processo de planejamento estrutura-se nas fases de planejamento estratégico e planejamento operacional.

\section{Execução}

$\mathrm{Na}$ fase de execução, implementam-se as ações estabelecidas no planejamento operacional, procurando dinamizar o conjunto de eventos que melhor propiciará a obtenção dos objetivos e metas previstos. Esse processo abrange a determinação das tarefas que serão realizadas, quem irá executá-las, como agrupá-las, quem se reportará a quem e quem tornará as decisões (DRUCKER, 1998). Para Osterwalder et al. (2011) entende-se que:

A proporção e a velocidade com a qual modelos de negócios inovadores estão transformando a indústria agora são sem precedentes. Para empreendedores, executivos, consultores e acadêmicos, este é o momento certo para tentar compreender o impacto desta extraordinária evolução, e lidar metodicamente com seus desafios.

Ao que se refere em relação à importância da controladoria e da função do controller no processo de tomada de decisão na gestão empresarial é fundamental dar ênfase as estratégias para a definição do público-alvo, determinando-se as vantagens e as desvantagens, e principalmente, avaliar todas as variáveis a fim de minimizar os riscos e maximizar os potenciais competitivos de sucesso.

\section{Controle}

Entende-se que o controle está relacionado com a Administração, nesse contexto, controlar significa verificar as condições de determinadas coisas, com tudo compreende- se que o controle é um substantivo utilizado para definir o domínio ou o poder. Conforme Bianchi (2005) diz que:

O controle do processo de planejamento permite verificar se todas as áreas da organização estão desempenhando suas atividades de maneira correta, ou mesmo se os resultados alcançados correspondem às expectativas contidas no planejamento. Os resultados atingidos são comparados aos orçados, indicando a possibilidade de se apontar os desajustes ocorridos durante o processo a fim de solucioná-los.

Diante dessas concepções, observa-se que o controle diz a respeito à preocupação dos gestores em assegurar que os recursos sejam obtidos e aplicados eficazmente na realização dos objetivos da empresa. $O$ controle, nessa perspectiva, pode ser entendido como um processo no qual a empresa segue os planos e as 
políticas da administração. É um processo recorrente que não tem princípio ou fim definíveis (FIGUEIREDO, 1997).

\section{CONCLUSÃO}

É evidente, a importância do papel da controladoria como órgão de extrema necessidade ou "peçachave" para eficiência empresarial e organizacional. No processo de gestão empresarial, como uma unidade administrativa definida na estrutura organizacional, com o propósito de oferecer o devido suporte e apoio a consecução dos objetivos institucionais.

Dessa forma a controladoria assume que a empresa deve ser vista como um conjunto de ações e esforços centralizados num determinado fim, ou seja, cumprir sua missão. Para isso, entende que a eficácia, abrangendo a produtividade, a eficiência, a adaptabilidade, geração de valor aos acionistas, clientes e colaboradores, consiste, por conseguinte, na premissa básica que deve nortear as ações dos diversos gestores. O conceito de gestão foi abordado representando um conjunto de princípios, crenças, valores, normas e ideais utilizando para o processo de tomada de decisão e de eficácia empresarial, caracterizando em três etapas: planejamento, execução e controle.

Através da controladoria, as informações devem atender as necessidades fiscais e gerenciais, utilizando da contabilidade financeira e gerencias e repassadas aos gestores e ao controller na forma de relatórios com informações objetivas, claras e oportunas. Cabe ao controller interpretar as informações contábeis e comunicá-las aos gestores, mostrando as eficiências ou deficiências dos processos.

Verificou-se que o controller é delineador e o gestor das informações contábil-gerenciais, responsáveis por unir, analisar, conferir e preparar os relatórios para tomada de decisões, controlando as atividades desenvolvidas pelas diversas áreas e departamentos da empresa.

Assim, a missão da controladoria é tornar a empresa viável a todos que direta ou indiretamente dela participam disponibilizando instrumentos de controle de gestão que influenciem mudanças comportamentais e estruturais nas entidades, no sentido da otimização dos resultados, conciliando os diversos interesses e necessidades entre todas as áreas da empresa, participando como coordenadora do processo de gestão empresarial.

Comum adequado conhecimento da realidade empresarial, em seus aspectos técnicos, econômicofinanceiros e políticos, aliado ao conhecimento de técnicas de implementação e utilização de recursos que permitem transformar dados em informações, e com auxilio imprescindível da controladoria e seu representante - o controller - criam algumas das condições necessárias a um eficaz posicionamento da empresa no ambiente macroeconômico empresarial.

\section{REFERÊNCIAS}

ALMEIDA, L. B.. Controladoria. In: CATELLI, A.. Controladoria: uma abordagem da gestão econômica - GECON. São Paulo: Atlas, 2001.
ALMEIDA, L. B.; PARISI, C.; PEREIRA, C. A.. Controladoria. In: CATELLI, A.. Controladoria: Uma Abordagem da Gestão Econômica - GECON. São Paulo: Atlas, 1999. 
BIANCHI, M.. A controladoria como um mecanismo interno de governança corporativa e de redução dos conflitos de interesse entre principal e agente. Dissertação (Mestrado em Ciências Contábeis) Universidade do Vale do Rio dos Sinos, São Leopoldo, 2005.

BRITO, O.. Controladoria de risco: retorno em instituições financeiras. São Paulo: Saraiva, 2003.

CHIAVENATO, I.. Empreendedorismo: dando asas ao espírito empreendedor. São Paulo: Saraiva, 2004.

DEL VALLE, D.; BEZERRA, E. C.; TAMURA, S. M.. 0 papel do "controler" nas organizações. Pesquisa Acadêmica. São Paulo: FEA-USP, 2002.

DRUCKER, P. F.. Introdução à administração. São Paulo: Pioneira, 1998.

FERREIRA JUNIOR, L.. Um estudo sobre a importância do Controller para as empresas. Monografia (Graduação) - Universidade Católica de Pernambuco, 2007.

FIGUEIREDO, S.; CAGGIANO, P. C.. Controladoria Teoria e Prática. São Paulo: Atlas, 1993.

FLORIANI, A. R.. Controladoria como geradora de informações para subsidiar decisões administrativas. Revista de Negócios, Blumenau, v.6, n.3, p.29-38, 2001.

HORNGREN, C. T.. Introdução à Contabilidade Gerencial. Rio de Janeiro: Prentice-Hall do Brasil, 1985.

KANITZ, M. S. B.. Demonstrações de Fluxo de Caixa Governamental: um modelo para as Prefeituras
Municipais. Monografia (Graduação) - Universidade Federal de Santa Catarina, Florianópolis, 1999.

MARION, J. C.. Contabilidade Empresarial. 11 ed. São Paulo: Atlas, 2005.

MOSIMANN, C. P.; FISCH, S.. Controladoria: seu papel na administração de empresas. 2 ed. São Paulo: Atlas, 1999.

NAKAGAWA, M.. Introdução à controladoria: conceitos, sistemas implementação. São Paulo: Atlas, 1993.

PEREIRA, C. A.. Ambiente, empresa, gestão e eficácia. In: CATELLI, A.. Controladoria: uma abordagem da gestão econômica GECON. São Paulo: Atlas, 1999.

PEREZ JÚNIOR, J. H.; PESTANA, A. O.; FRANCO, S. P. C. Controladoria de gestão: teoria e prática. São Paulo: Atlas, 1997.

ROESCH, S. M. A.. Projetos de estágio e de pesquisa em Administração: guia para estágios, trabalho de conclusão, dissertações e estudos de caso. 2 ed. São Paulo: Atlas, 1999.

RONCHI, L.. Controle Econômico e Financeiro para alta administração. 2 ed. São Paulo: Atlas, 1999.

TUNG, N. H.. Controladoria financeira das empresas: uma abordagem prática. 3 ed. São Paulo: Universidade Empresas, 1993.

WAHLMANN, G. C.. Um estudo exploratório sobre a atividade de controladoria nas microempresas na cidade de Ubatuba. Monografia (Graduação em Ciências Contábeis) - Faculdade Integradas Módulos, Caraguatatuba, 2003.

A CBPC - Companhia Brasileira de Produção Científica (CNPJ: 11.221.422/0001-03) detém os direitos materiais desta publicação. Os direitos referem-se à publicação do trabalho em qualquer parte do mundo, incluindo os direitos às renovações, expansões e disseminações da contribuição, bem como outros direitos subsidiários. Todos os trabalhos publicados eletronicamente poderão posteriormente ser publicados em coletâneas impressas sob coordenação da Sustenere Publishing, da Companhia Brasileira de Produção Científica e seus parceiros autorizados. Os (as) autores (as) preservam os direitos autorais, mas não têm permissão para a publicação da contribuição em outro meio, impresso ou digital, em português ou em tradução. 